\title{
sciendo
}

Int. J. of Applied Mechanics and Engineering, 2019, vol.24, No.1, pp.91-103

DOI: 10.2478/ijame-2019-0006

\section{REACTIVE POLLUTANTS DISPERSION MODELING IN A STREET CANYON}

\author{
A. MERAH ${ }^{*}$ \\ Centre de Recherche Scientifique et Technique en Analyses Physico-Chimiques \\ BP 384, Siège ex-Pasna Zone Industrielle \\ Bou-Ismail CP 42004, Tipaza, ALGERIE \\ E-mail: aissa102002@yahoo.fr \\ Laboratoire de Mécanique Appliquée LMA \\ Université des Sciences et de la Technologie d'Oran Mohamed BOUDIAF (USTO-MB) \\ ALGERIE \\ A. NOUREDDINE \\ Laboratoire de Mécanique Appliquée LMA \\ Université des Sciences et de la Technologie d'Oran Mohamed BOUDIAF (USTO-MB) \\ ALGERIE
}

\begin{abstract}
Reactive pollutant dispersion in a 3-D urban street canyon is numerically investigated using a computational fluid dynamics (CFD) code (Ansys-CFX), with the $k-\varepsilon$ turbulence model and includes transport equations for $\mathrm{NO}, \mathrm{NO}_{2}$, and $\mathrm{O}_{3}$ with simple photochemistry. An area emission source of $\mathrm{NO}$ and $\mathrm{NO}_{2}$ was considered in the presence of background $\mathrm{O}_{3}$ with an ambient wind perpendicular to the along-canyon direction. The results showed that the magnitude of $\mathrm{NO}_{\mathrm{x}}\left(\mathrm{NO}+\mathrm{NO}_{2}\right)$ concentrations on the leeward side of the upstream buildings was much larger than the windward side of the downstream building, due to the entrainment and dispersion of traffic emissions by the primary vortex. The reverse is the case for ozone with higher concentrations on the windward side compared to the leeward side.

The model has been validated against no-reactive pollutant experimental data of the wind tunnel experiments of Hoydysh and Dabberdt [1]
\end{abstract}

Key words: street canyon, reactive pollutant, computational fluid dynamics (CFD), $\mathrm{NOx}, \mathrm{O}_{3}$.

\section{Introduction}

Street canyons have for many years been an area of active study on air quality modeling, both in terms of predicting actual roadside exposure to pollution and as a more theoretical test-case for using different numerical models (Garmory et al. [2]).

Numerous investigations have been devoted to elucidate wind flow and pollutant transport in urban street canyons using wind tunnel experiments such as Kastner-Klein and Plat [3] and Meroney and Pavageau [4], numerical models described in Oke [5] and Cheng et al. [6], and deploying full-scale experiments by Johnson and Hunter [7] and Rotach [8]. Numerical studies of reactive pollutant dispersion in an urban street canyon are few in the literature compared with the simulations of passive pollutant.

* To whom correspondence should be addressed 
The studies conducted so far by various researchers have not been comprehensive enough to demonstrate the reactive pollutant flow and dispersion within the street canyon.

There are literally thousands of chemical compounds, undergoing an even larger number of chemical reactions in the atmosphere. Because of the current limited computing power, photochemical models are unable to include all the atmospheric chemical species and reactions simultaneously. Therefore, simplified, or the most representative, chemical mechanisms are introduced into photochemical models to provide a computationally viable means of representing what is understood about the chemical dynamics of trace compounds in street canyons.

The main aim of this paper is to model reactive pollutant dispersion in 3-D urban street canyon. A CFD (computational fluid dynamics) code was used (ANSYS-CFX), with a standard k- $\varepsilon$ turbulence model, incorporating simple photochemistry reactions. Through this combination, the dominant processes in determining canyon atmospheric composition will be investigated.

\section{Material and methods}

\subsection{Simulation of selected street}

The street canyon chosen for the study is located in a medium sized city, Kozani, in Northwestern Greece. It is a heavily industrialized area, due to lignite power stations that contribute about $70 \%$ of total electrical energy produced in Greece.

The street is simulated in CFX One-way Street, the width of the street varies with an average value of $10 \mathrm{~m}$ and with a length of $95 \mathrm{~m}$. This street has about 19 building with heights varying between $3 \mathrm{~m}$ and $18 m$ (Fig.1).

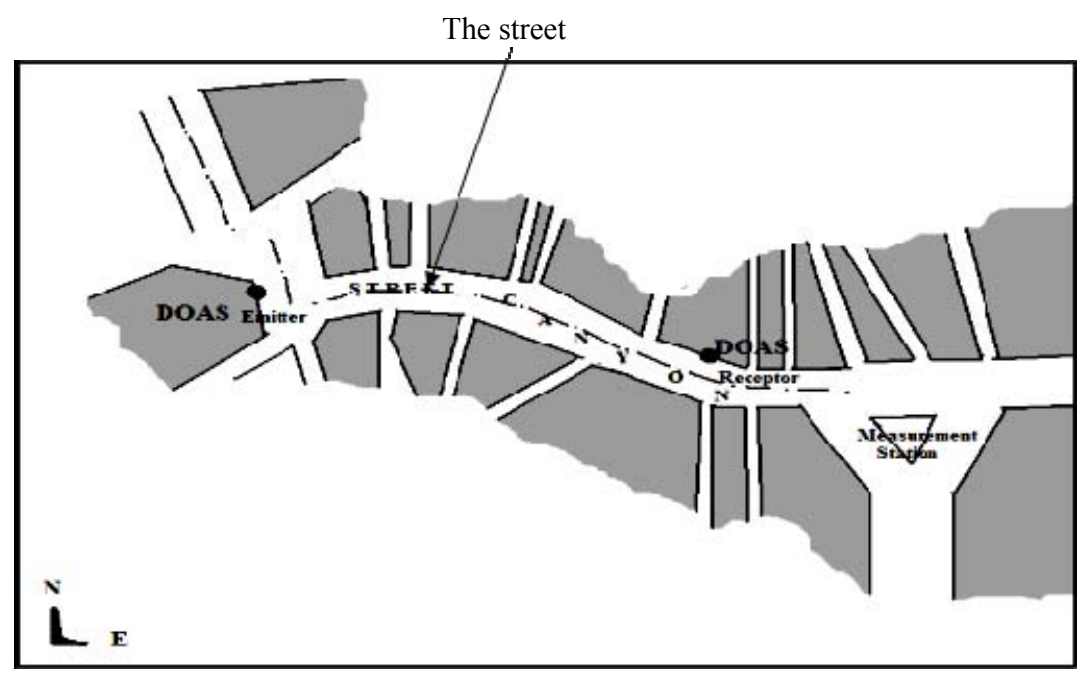

Fig.1. Map of the street with the surrounding buildings.

\subsection{Computational domain}

Figure 2 illustrates the computational domain, and building configuration. The origin of the coordinate system is located at the left bottom corner of the street in the computational domain. The domain size is $95 \mathrm{~m}$ in the $x$-direction, $16 \mathrm{~m}$ in the $y$-direction, $21 \mathrm{~m}$ in the $z$-direction. 

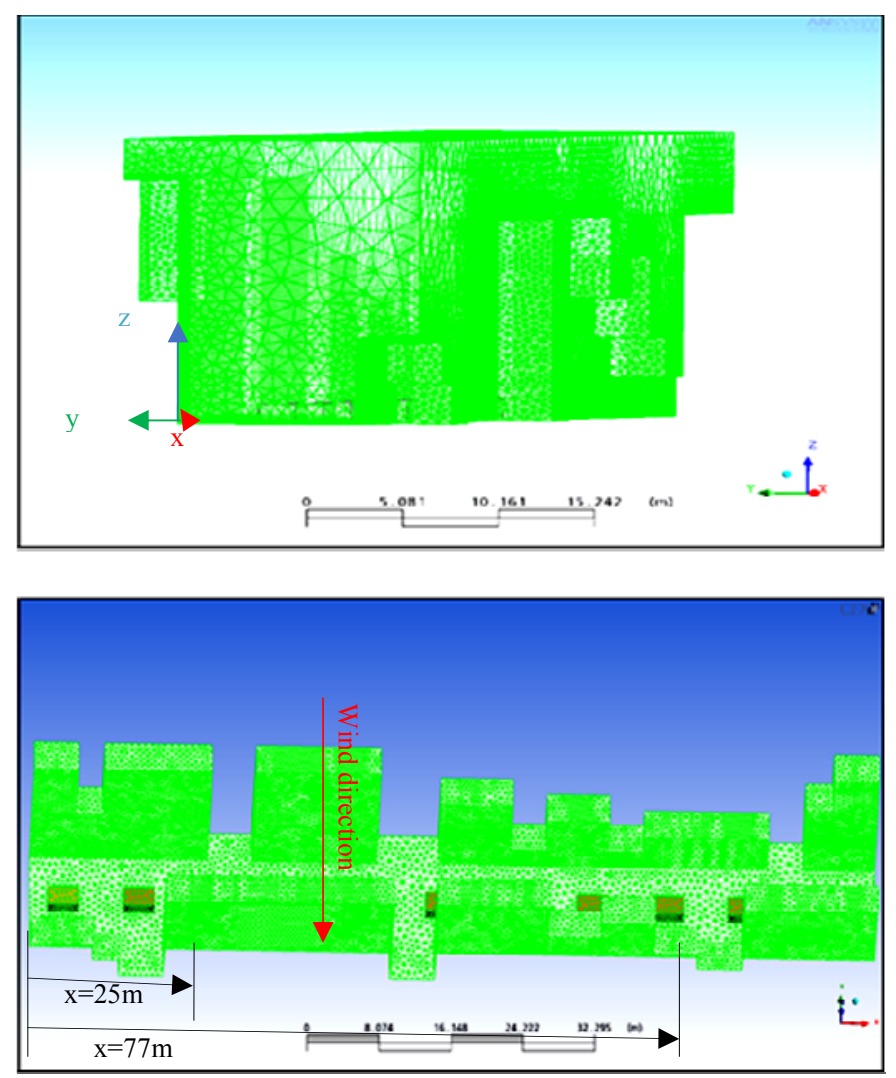

Fig.2. Computational domain and building configuration.

\subsection{Model description}

Computational fluid dynamics (CFD) modelling is based on the governing fluid flow and dispersion equations, which are derived from basic conservation and transport principle:

-the mass conservation (continuity) equation

-the three momentum conservation (Navier-Stokes) equations

-the transport equation for pollution concentration.

The air within the street canyon can be regarded as an incompressible turbulent flow and the air and pollutants densities are assumed constant. These assumptions are reasonable for lower atmosphere environment as described by Sini et al. [9].

The turbulence production due to the buoyancy effect is not included because the thermal effect in the street canyon is not taken into consideration in the present study. For the street canyon problem, the standard $k$ - $\varepsilon$ turbulence model governing equations are expressed as the continuity equation

$$
\frac{\partial U_{i}}{\partial x_{i}}=0
$$

the momentum equation

$$
\frac{\partial U_{i}}{\partial t}+U_{j} \frac{\partial U_{i}}{\partial x_{i}}=-\frac{1}{\rho} \frac{\partial \bar{p}}{\partial x_{i}}+\frac{\partial}{\partial x_{j}}\left(\cup \frac{\partial U_{i}}{\partial x_{j}}-\overline{u_{i}^{\prime} u_{j}^{\prime}}\right),
$$

$k$ and $\varepsilon$ transport equations in the standard $k-\varepsilon$ model 


$$
\begin{aligned}
\frac{\partial k}{\partial t}+\boldsymbol{V} \operatorname{grad} k & =\operatorname{div}\left(\frac{v_{t}}{\sigma_{k}} \operatorname{grad} k\right)+P-\varepsilon, \\
\frac{\partial \varepsilon}{\partial t}+\boldsymbol{V} \operatorname{grad} \varepsilon & =\operatorname{div}\left(\frac{\mathrm{v}_{t}}{\sigma_{\varepsilon}} \operatorname{grad} \varepsilon\right)+\frac{\varepsilon}{k}\left(C_{\varepsilon_{1}} P-C_{\varepsilon_{2}} \varepsilon\right),
\end{aligned}
$$

$k$ is the turbulent kinetic energy; $\varepsilon$ denotes the turbulent dissipation rate.

$P$ is the production of $k$.

where:

$$
\mathrm{v}_{t}=C_{\mu} \frac{k^{2}}{\varepsilon} ; \quad P=2 \mathrm{v}_{t} S_{i j} S_{i j} ; \quad \overline{u_{i}^{\prime} u_{j}^{\prime}}=-2 \mathrm{v}_{t} S_{i j}+\frac{2}{3} k \delta_{i j} ; \quad S_{i j}=\frac{1}{2}\left[\frac{\partial U_{i}}{\partial x_{j}}+\frac{\partial U_{j}}{\partial x_{i}}\right] .
$$

Table 1. The constants for the $k-\varepsilon$ turbulence model.

\begin{tabular}{|llcrc|}
\hline$C_{\mu}$ & $\sigma_{k}$ & $\sigma_{\varepsilon}$ & $C_{\varepsilon_{1}}$ & $C_{\varepsilon_{2}}$ \\
\hline 0.09 & 1 & 1.3 & 1.44 & 1.92 \\
\hline
\end{tabular}

Pollutant concentration is calculated with the convective-diffusion equation

$$
\frac{\partial C_{i}}{\partial t}+U_{j} \frac{\partial C_{i}}{\partial x_{j}}=\frac{\partial}{\partial x_{j}}\left(K_{t} \frac{\partial C_{i}}{\partial x_{j}}\right)+S_{i}
$$

where $C_{i}$ denotes the pollutant concentration, $K_{t}$ is the eddy diffusivity coefficient; and $S_{i}$ represents all sources and sinks terms.

\subsection{Chemical coupling of $\mathrm{O}_{3}$, NO, and $\mathrm{NO}_{2}$}

The reactive pollutants we are concerned with in this study are nitrogen oxide NO and nitrogen dioxide $\mathrm{NO}_{2}$, which are supposed to be emitted from automobiles within the street canyon in the presence of background ozone $\mathrm{O}_{3}$ (Merah et al. [10]).

The chemical reactions considered are

$$
\begin{aligned}
& \mathrm{NO}_{2}+\text { sunlight }(\lambda<420 \mathrm{~nm}) \rightarrow \mathrm{NO}+\left(\mathrm{O}^{3 \mathrm{p}}\right) \\
& \left(\mathrm{O}^{3 \mathrm{p}}\right)+\mathrm{O}_{2}+\mathrm{M} \rightarrow \mathrm{O}_{3}+\mathrm{M} \\
& \mathrm{O}_{3}+\mathrm{NO} \rightarrow \mathrm{NO}_{2}+\mathrm{O}_{2}
\end{aligned}
$$

$M$ represents a molecule $\left(\mathrm{N}_{2}\right.$ or $\mathrm{O}_{2}$ or another third molecule).

\subsubsection{Equations of state}

- Ideal gas equation of state (e.g. $\mathrm{NO}, \mathrm{NO}_{2}$ )

For an ideal gas, the equation of state is

$$
\rho=\frac{M \times P}{R \times T}
$$


where $M$ is the molecular weight of the gas, $\rho$ is the density, $R$ is the universal gas constant, $T$ is the temperature, and $P$ is the pressure.

- Redlich-Kwong equation of state (e.g. $\mathrm{O}_{2}, \mathrm{O}_{3}$ )

The Redlich-Kwong equation described in Giorgio [11] can handle various pure fluids, and includes ozone, oxygen, carbon monoxide, hydrogen, helium, and argon, etc.

The form of this equation of state is used by ANSYS-CFX code and is given by

$$
p=\frac{R \times T}{v-b+c}-\frac{a(T)}{v(v+b)}
$$

where:

$$
a=a_{0}\left(\frac{T}{T_{c}}\right)^{-n}, \quad b=\frac{0.08664 R T_{c}}{p_{c}}, \quad c=\frac{R T_{c}}{p_{c}+\frac{a_{0}}{v_{c}\left(v_{c}+b\right)}}+b-v_{c}
$$

and:

$$
a_{0}=\frac{0.42747 R^{2} T_{c}^{2}}{p_{c}}, \quad n=0.4986+1.2735 w+0.4754 w^{2}, \quad w=-\log _{10}\left(\frac{p_{v}}{p_{c}}\right)-1 .
$$

$P_{c}$ and $T_{c}$ are the critical pressure and critical temperature respectively.

The vapour pressure $p_{v}$ is calculated at $T=0.7 T_{c}$.

\subsubsection{Reaction rate type}

Chemical kinetics characterizes the rate at which chemical species appear or disappear.

For the reactions $R_{1}$ and $R_{2}$ the kinetic rate constant (of reaction) is a function of temperature and is given in the form

$$
k(T)=A \times T^{\beta} \exp \left(\frac{-E_{a}}{R \times T}\right)
$$

This equation is called the Arrhenius equation (used by ANSYS-CFX), where $A$ is a pre-exponential factor, $\beta$ is the temperature exponent, $R$ is the universal gas constant, $T$ is the temperature, and $E_{a}$ is the activation energy.

Table 2. The rate constant parameters for the reactions $R_{1}$ and $R_{2}$.

\begin{tabular}{|l|llr|}
\hline Reaction & $A$ & $E_{a}$ & $\beta$ \\
\hline$R_{1}$ & $6.10^{-34}$ & 0.0 & -2.3 \\
$R_{2}$ & $2.10^{-12}$ & 2.782 & 0.0 \\
\hline
\end{tabular}

where $E_{a}$ in $\mathrm{kcal} / \mathrm{mol}$, and $A$ in $\mathrm{cm}$, molecule.

For the reaction $R_{0}$, following Baker et al. [12], the photolysis rate is calculated using the expression

$$
J_{\mathrm{NO}_{2}}=8.14 \times 10^{-3} \times\left[0.97694+8.14 \times 10^{-4} \times(T-273.15)+4.5173 \times 10^{-6} \times(T-273.15)^{2}\right]
$$

where $T$ is in $K$ and the unit of $J_{\mathrm{NO} 2}$ is $s^{-1}$. 


\subsection{Initializations}

\section{- Emission sources}

The emission sources considered in this study are sub-domains (volume sources), created along the street in the $x$-direction (11 sub-domains or cars), with the size of $3.5 m \times 2 m \times 1.48 m$ (each car), and the distance between two cars is $5 \mathrm{~m}$. The vehicles were assumed to emit $\mathrm{NO}\left(90 \%\right.$ of $\left.\mathrm{NO}_{\mathrm{x}}\right), \mathrm{NO}_{2}\left(10 \%\right.$ of $\left.\mathrm{NO}_{\mathrm{x}}\right)$. We estimate the emission rate for each car, as NO emission rate of $18.3 \mu \mathrm{g} / \mathrm{m}^{3} \mathrm{~s}$, and $2.03 \mu \mathrm{g} / \mathrm{m}^{3} \mathrm{~s}$ of $\mathrm{NO}_{2}$ (Merah et al. [10]). A background ozone concentration of $70 \mu \mathrm{g} / \mathrm{m}^{3}$ was then set for the entire domain gathered from experimental data DOAS (Baker et al. [12] and Stern and Yamartino [13]).

\section{- Mass fractions} as follows:

For initial values of mass fraction, we used the values measured by DOAS system (average values),

For ozone the mass fraction was $f_{\mathrm{O} 3}=5.8 \times 10^{-8}\left(70 \mu \mathrm{g} / \mathrm{m}^{3}\right)$.

For $\mathrm{NO}_{2}$ the mass fraction was $f_{\mathrm{NO} 2}=2.025 \times 10^{-8}\left(24 \mu \mathrm{g} / \mathrm{m}^{3}\right)$.

For NO the mass fraction was $f_{\mathrm{NO}}=1.02 \times 10^{-8}\left(12 \mu \mathrm{g} / \mathrm{m}^{3}\right)$.

\section{- Inflow boundary}

In this study, the wind direction is perpendicular to the street (opposite to the y-direction), and at the inflow, the wind velocity profile described by a power law (Yoshihide et al. [14])

$$
U(z)=U_{r e f}\left(\frac{z}{z_{r e f}}\right)^{\alpha}
$$

where $z_{\text {ref, }} U_{\text {ref }}$ are the reference height $(10 \mathrm{~m})$ and reference velocity $(1.5 \mathrm{~m} / \mathrm{s})$, respectively, $\alpha$ is the power law exponent (0.299), (Fig.3).

The pressure and temperature were specified as $1 \mathrm{~atm}$ and $25^{\circ} \mathrm{C}$, respectively.
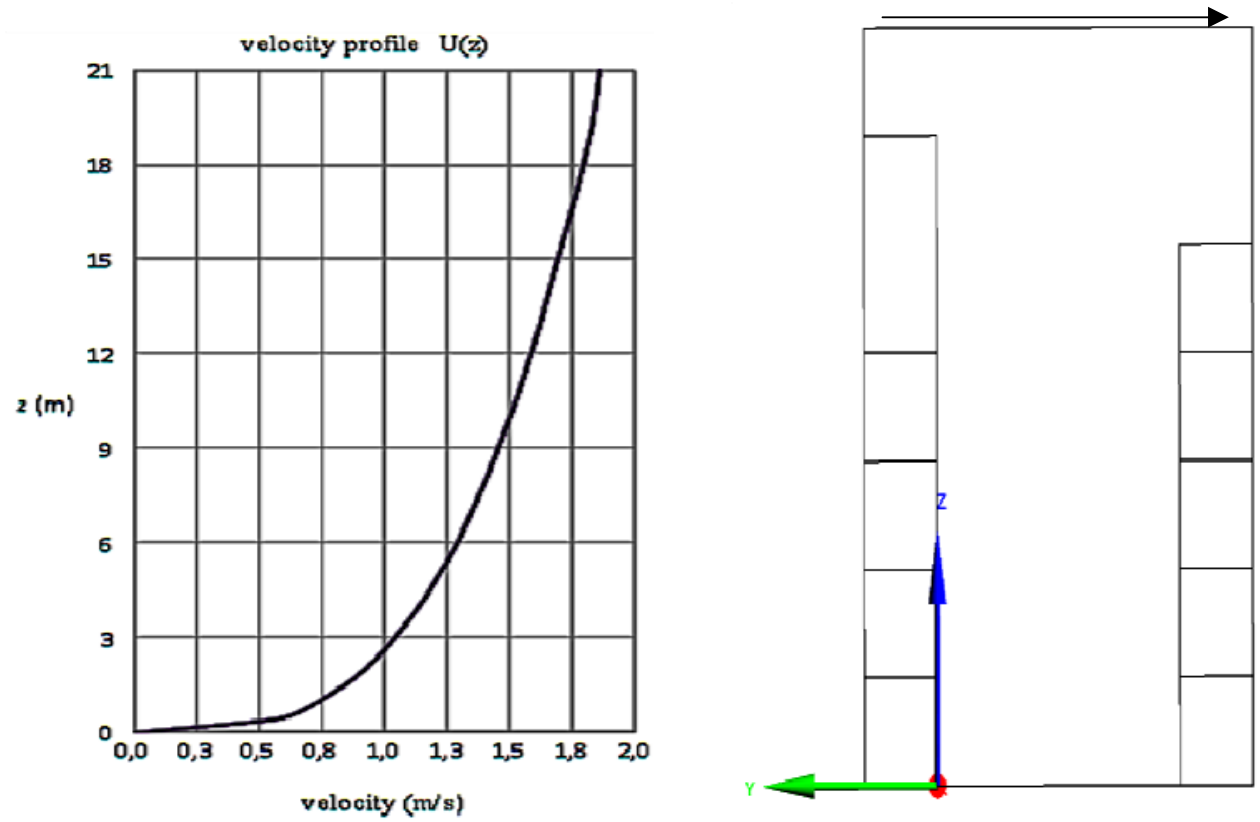

Fig.3. Velocity profile plot at inflow boundary (left), wind direction (perpendicular to the street) (right). 


\subsection{Model validation (test)}

No experimental data on reactive pollutant concentration in a street canyon are available currently, so comparisons are made with no-reactive pollutant experimental data of the wind tunnel experiments (wind perpendicular to the street canyon). For testing the performance of the present model, simulations have been performed with flow parameters and geometry of the test section the same as those of the experiment carried out by Hoydysh and Dabberdt [1].

Before plotting, the model's and the experiment's values were normalized each one with its maximum concentration $\mathrm{C}_{\max }$, occurring at the upwind side.

Figure 4 shows an agreement between the numerical simulation and wind tunnel experiment results. Both the calculated and measured results show that the magnitude of dimensionless pollutant concentrations on the leeward side is larger than the windward side. On the leeward side, the pollutant concentrations decrease from the floor to the roof of the upstream building, while the pollutant concentrations are almost constant along the height of the building downstream of the windward side. The normalized concentrations on the leeward side are under-predicted, especially at the higher part of the leeward side.

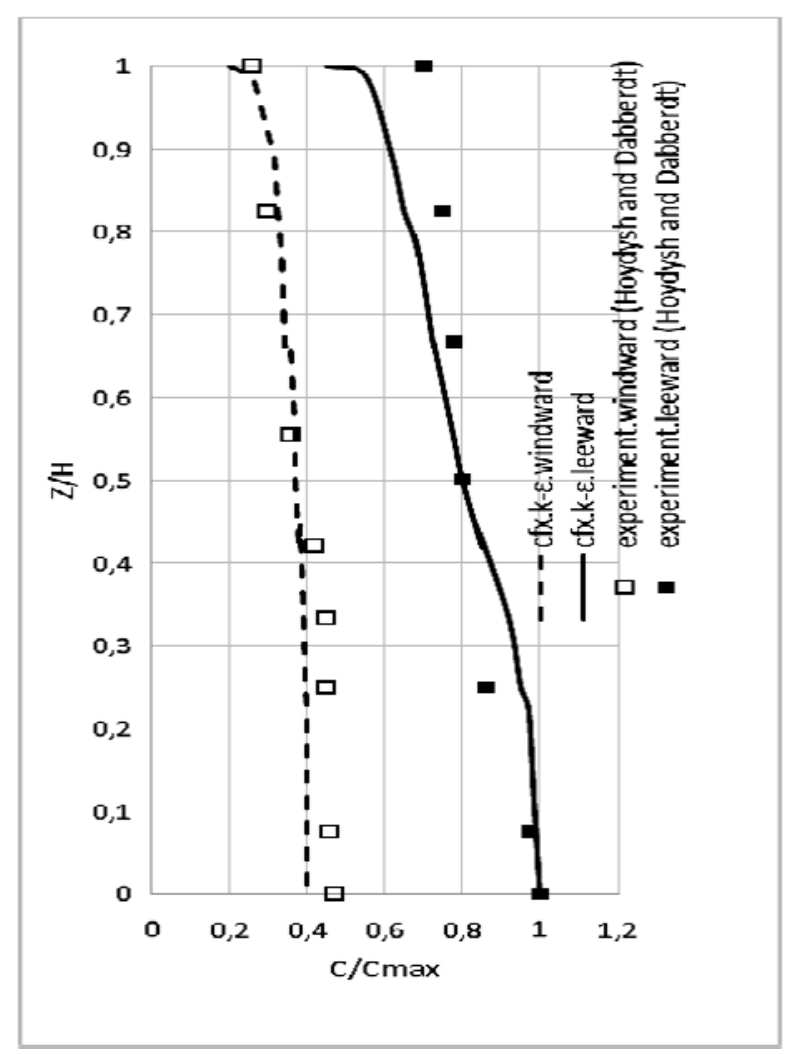

Fig.4. Comparison of the computed normalized concentration profiles at leeward and windward sides with experimental data from Hoydysh and Dabberdt [1].

\section{Results and discussion}

The effect of wind direction was crucial and a key factor determining the dispersion of pollutants. It was very interesting to see how the concentration distribution is behaving with respect to the flow field (Merah et al. [10]). 
The spatial distribution pattern in the $\mathrm{NO}$ and $\mathrm{NO}_{2}$ concentration fields reflects the existence of a vortex in the street canyon (for the two positions of $x=25 \mathrm{~m}$ and $x=77 \mathrm{~m}$ (Fig.2) on the $x-y$ plane), that is, the concentration is higher near the downwind building than near the upwind building (Fig.5).

Near the street bottom, $\mathrm{NO}$ and $\mathrm{NO}_{2}$ concentrations are higher $\left(1.82 \times 10^{-7} \mathrm{~kg} / \mathrm{m}^{3}, 2.42 \times 10^{-7} \mathrm{~kg} / \mathrm{m}^{3}\right.$ at $x=77 \mathrm{~m}$, and $2.4 \times 10^{-7} \mathrm{~kg} / \mathrm{m}^{3}, 2.5 \times 10^{-7} \mathrm{~kg} / \mathrm{m}^{3}$ at $x=25 \mathrm{~m}$, respectively) near the corner of the downwind building than near the street center due the primary vortex (Figs 5 and 6) recirculates emitted pollutants therein. This also accounts for the low concentrations of $\mathrm{O}_{3}$ within this region. In addition, the oxidation of $\mathrm{NO}$ (by $\mathrm{O}_{3}$ ) to $\mathrm{NO}_{2}$ leads to a significant increase of the $\mathrm{NO}_{2}$ concentration levels.

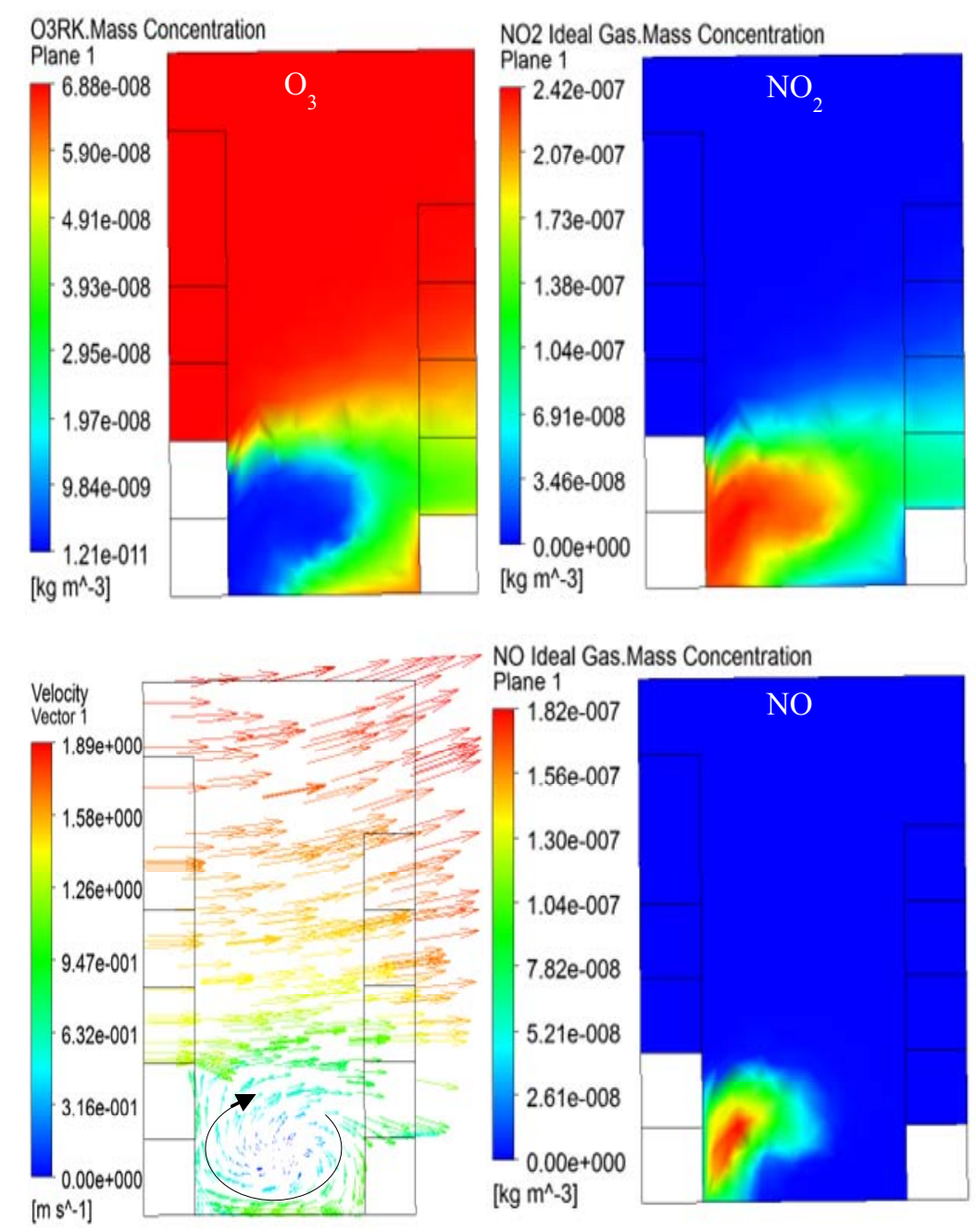

Fig.5. $\mathrm{O}_{3}, \mathrm{NO}_{2}, \mathrm{NO}$ concentrations; and velocity vectors on $y-z$ plane at $x=77 m$.

On the other hand, $\mathrm{O}_{3}$ concentration is high $\left(6.88 \times 10^{-8} \mathrm{~kg} / \mathrm{m}^{3}\right)$ near the upper downwind region of the street canyon where the ambient ozone enters the canyon (Baik et al. [15]).

Most exchange takes place near the windward wall where air is entering the canyon from above the roof level and pollutants are able to escape.

A greater level of exchange toward the windward wall gives higher concentrations of $\mathrm{O}_{3}$ (greater than $4.5 \times 10^{-8} \mathrm{~kg} / \mathrm{m}^{3}, \mathrm{Fig} .6$ ), as $\mathrm{O}_{3}$-rich air enters the canyon from above. This occurs due to the relatively low concentrations of $\mathrm{NO}$ as emissions are not easily entrained into this region. As a result, less $\mathrm{NO}_{2}$ is formed by the reaction of $\mathrm{NO}$ with $\mathrm{O}_{3}$ and less $\mathrm{O}_{3}$ is consumed (Bright et al. [16]). 
It is interesting to observe in Fig.6 that under the increasing buildings height the amount of intrusion of ozone into the canyon has increased. It indicates that an increment of building height encourages the accumulation of ozone, and this corresponds to Yucong et al. [17] study.
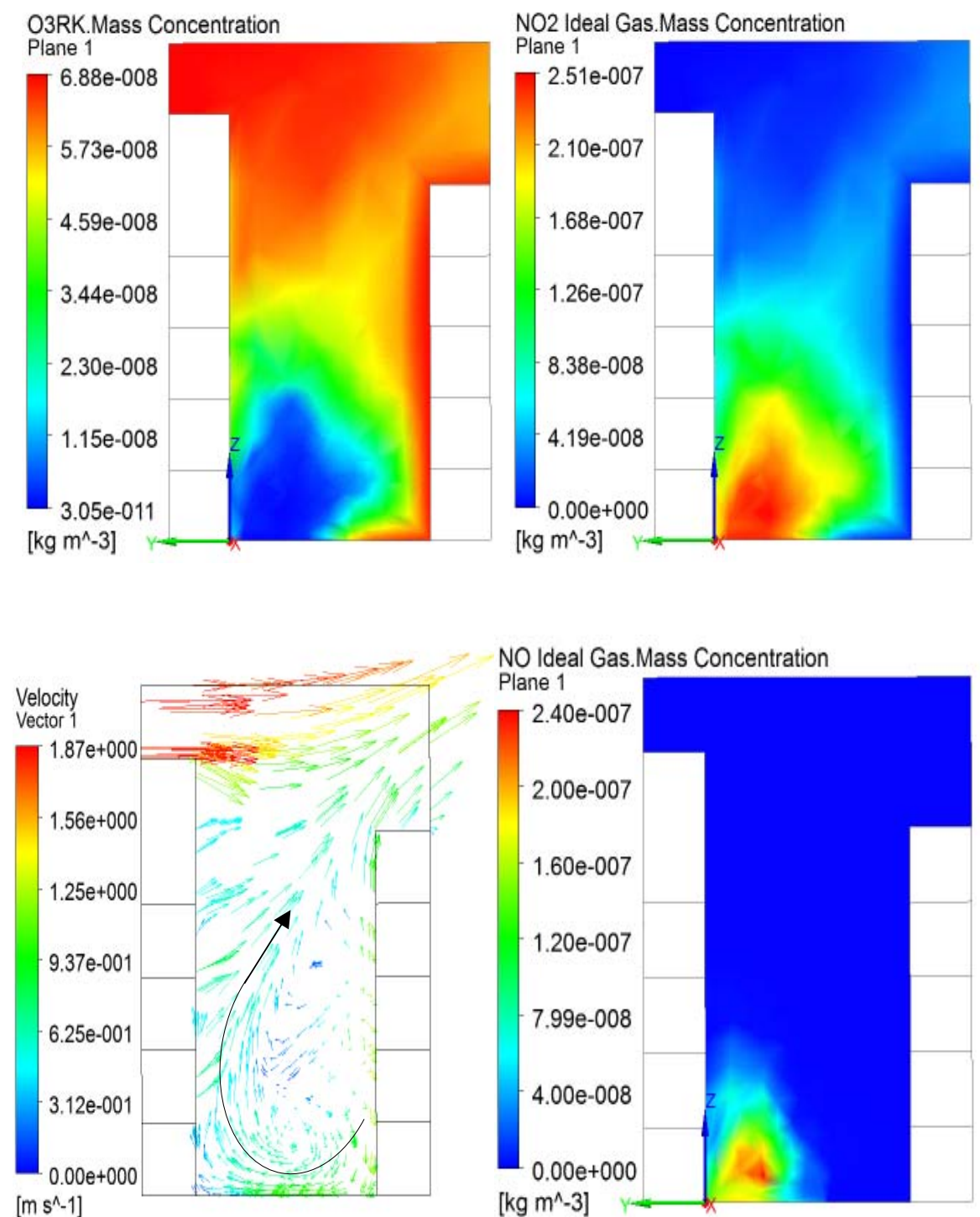

Fig.6. $\mathrm{O}_{3}, \mathrm{NO}_{2}, \mathrm{NO}$ concentrations; and velocity vectors on the $y-z$ plane at $x=25 \mathrm{~m}$.

For more understanding of the results above (Figs 5 and 6), we have selected the areas that have been affected significantly by the dispersion and interaction of pollutants (leeward side, windward side and at the ground level).

Figure 7 shows the concentration of pollutants at leeward side on the $y$-z plane for $x=77 \mathrm{~m}$ and $x=25$ $\mathrm{m}$ respectively.

At $x=77 \mathrm{~m}$ the concentration of $\mathrm{NO}$ and $\mathrm{NO}_{2}$ decreases significantly, from the values of $10^{-7} \mathrm{~kg} / \mathrm{m}^{3}$, $2.3 \times 10^{-7} \mathrm{~kg} / \mathrm{m}^{3}$ respectively, until zero when $z=7 \mathrm{~m}$ ( height of the leeward building). This is due to the effect of the layer at the roof level, the leeward wall acts to hinder the escape of pollutants. On the contrary, $\mathrm{O}_{3}$ concentration increases, from zero $(z=5 \mathrm{~m})$ to a maximum value of $6.88 \times 10^{-8} \mathrm{~kg} / \mathrm{m}^{3}$ (at $z=7 \mathrm{~m}$ ) where $\mathrm{O}_{3}$ enters the canyon (Fig.5). 
At $x=25 \mathrm{~m}$ differently to the previous case, the concentrations of $\mathrm{NO}$ and $\mathrm{NO}_{2}$ decrease slowly with increasing of $z$ level. This can be explained by increasing buildings height and the weak wind speed inside the street.

We also note that always a symmetric level was produced between ozone and $\mathrm{NO}_{2}$, which follow opposite trends (Triantafyllou et al. [18]).
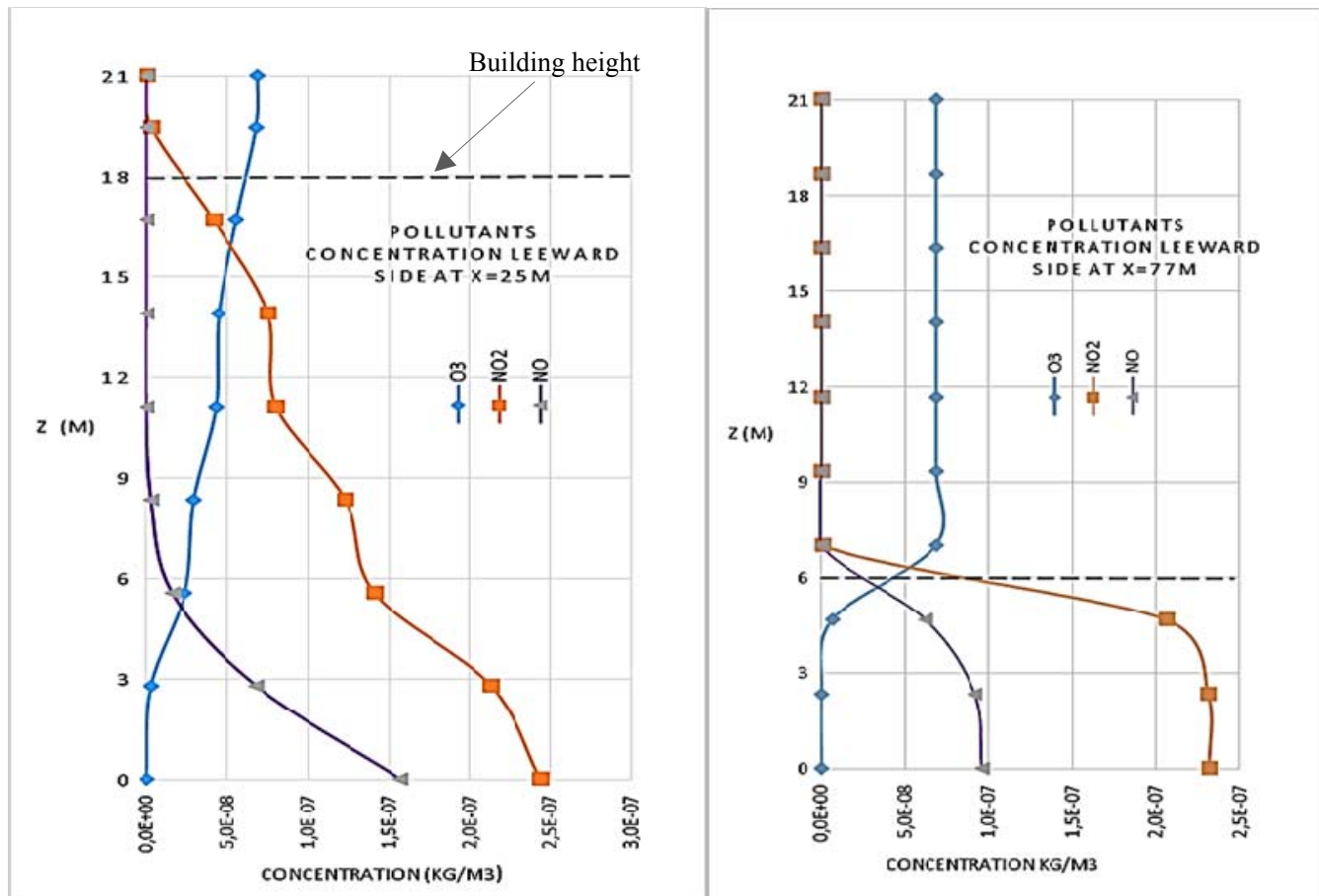

Fig.7. $\mathrm{O}_{3}, \mathrm{NO}_{2}$ and $\mathrm{NO}$ concentration at leeward side of street (for $x=77 \mathrm{~m}$ and $x=25 \mathrm{~m}$ ).

Figure 8 displays the pollutants concentration at windward side for $x=25$, and $77 \mathrm{~m}$. At $x=25 \mathrm{~m}$ (high buildings), the concentration of ozone remains high $\left(6.8 \times 10^{-8} \mathrm{~kg} / \mathrm{m}^{3}\right)$ until the level of $z=15 \mathrm{~m}$, then decreased slightly until $z=18 \mathrm{~m}$, and then increased again.

There was a very low concentration of $\mathrm{NO}_{2}$ except when $z=15 \mathrm{~m}$ to $20 \mathrm{~m}$, where its concentration increased a little bit $\left(2 \times 10^{-8} \mathrm{~kg} / \mathrm{m}^{3}\right)$. This slight increase in the concentration of $\mathrm{NO}_{2}$ and the decrease in $\mathrm{O}_{3}$ concentration was due to the exit of pollutants from the upper region (more than $15 \mathrm{~m}$ ), (Fig.6).

At $x=77 \mathrm{~m}$ (low building), we observed that the $\mathrm{NO}_{2}$ concentration increased from $2.6 \times 10^{-8} \mathrm{~kg} / \mathrm{m}^{3}$ $(z=0)$ to a peak value $7.8 \times 10^{-8} \mathrm{~kg} / \mathrm{m}^{3}(z=7 \mathrm{~m})$, then decreased to zero at $z=15 \mathrm{~m}$.

The ozone concentration decreased from $6 \times 10^{-8} \mathrm{~kg} / \mathrm{m}^{3}(z=0)$ to a low value $4.4 \times 10^{-8} \mathrm{~kg} / \mathrm{m}^{3}(z=7 \mathrm{~m})$, then increased to a peak value $6.8 \times 10^{-8}(z=15 \mathrm{~m})$, we note that the increasing of $\mathrm{NO}_{2}$ concentration and decreasing of $\mathrm{O}_{3}$ were significant at levels $z=3 m$ to $z=8 m$, this corresponds to the upper region from the windward wall, where the pollutants escape more than in the previous case $(x=25 \mathrm{~m})$. As shown in Fig.8, the NO concentration falls to almost zero (in both cases $x=25 \mathrm{~m}$ and $x=77 \mathrm{~m}$ ), because the dispersion of NO is limited in this region (windward side).

Figure 9 illustrates pollutants concentration at ground level $(x=25 m, x=75 m)$. $\mathrm{NO}$ and $\mathrm{NO}_{2}$ concentrations are high from $y=0 m$ (corner of leeward side) until $y=-4 m$ (near the street center); because the vortex (Figs 5 and 6) emitted the pollutants towards this region. While the ozone concentration was a little higher on the opposite side $(y=-7 m$ until $y=-10 m)$, due to the lack of NO there. 

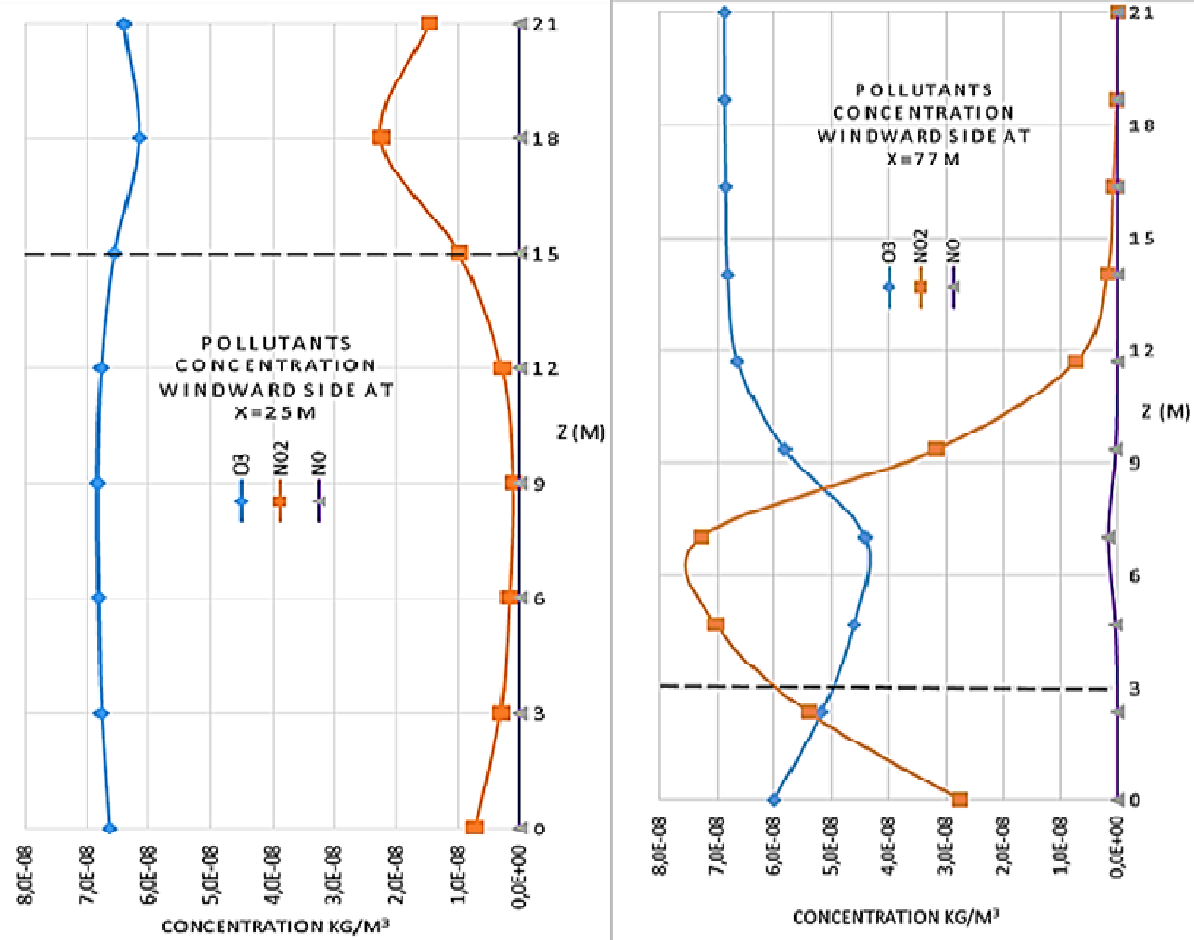

Fig.8. $\mathrm{O}_{3}, \mathrm{NO}_{2}$ and $\mathrm{NO}$ concentration at windward side of street (for $x=77 \mathrm{~m}$ and $x=25 \mathrm{~m}$ ).
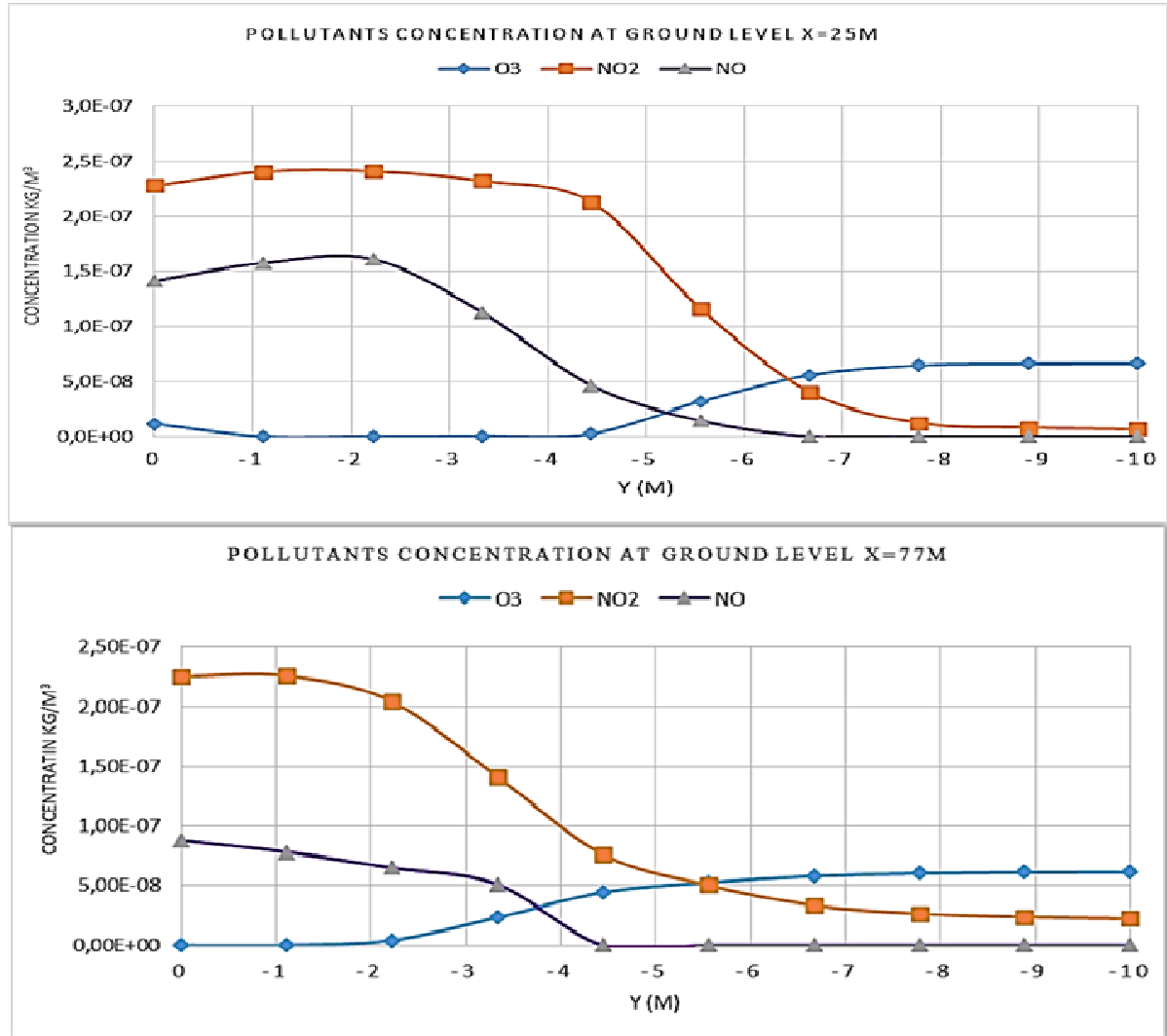

Fig.9. $\mathrm{O}_{3}, \mathrm{NO}_{2}$ and $\mathrm{NO}$ concentration at ground level of the street (for $x=77 \mathrm{~m}$ and $x=25 \mathrm{~m}$ ). 


\section{Conclusion}

The results indicated that the wind direction and its distribution play a significant role in determining pollutants dispersion levels. The wind perpendicular to the street leads to accumulation of pollutants inside the street canyon with a different degree depending on buildings height; as the height of buildings increases, the pollution level increases. The results show that there are clear spatial patterns in the concentration of pollutants within the canyon with the highest concentrations of $\mathrm{NO}$ and $\mathrm{NO}_{2}$ found toward the leeward wall, near the bottom (corner), due to entrainment and transport of emissions by the vortex.

The lowest concentrations of $\mathrm{O}_{3}$ were found toward the leeward wall as a result of its reaction with $\mathrm{NO}$ to form $\mathrm{NO}_{2}$. The highest within-canyon concentrations of $\mathrm{O}_{3}$ were observed near the upper downwind region of the street canyon where ambient ozone enters the canyon. Also in the windward wall, there are relatively low concentrations of $\mathrm{NO}$ as emissions are not easily entrained into this region. As a result, less $\mathrm{O}_{3}$ is consumed.

It can be concluded that the obtained results are very interesting and prove that the CFD model (ANSYS-CFX) could be efficiently applied in urban street canyon photochemistry modelling. The present CFD model incorporates simple photochemistry, but could be a prototype to develop a CFD model with complex chemical processes for basic and applied research with a wide range of practical applications to urban atmospheric environmental problems.

\section{Nomenclature}

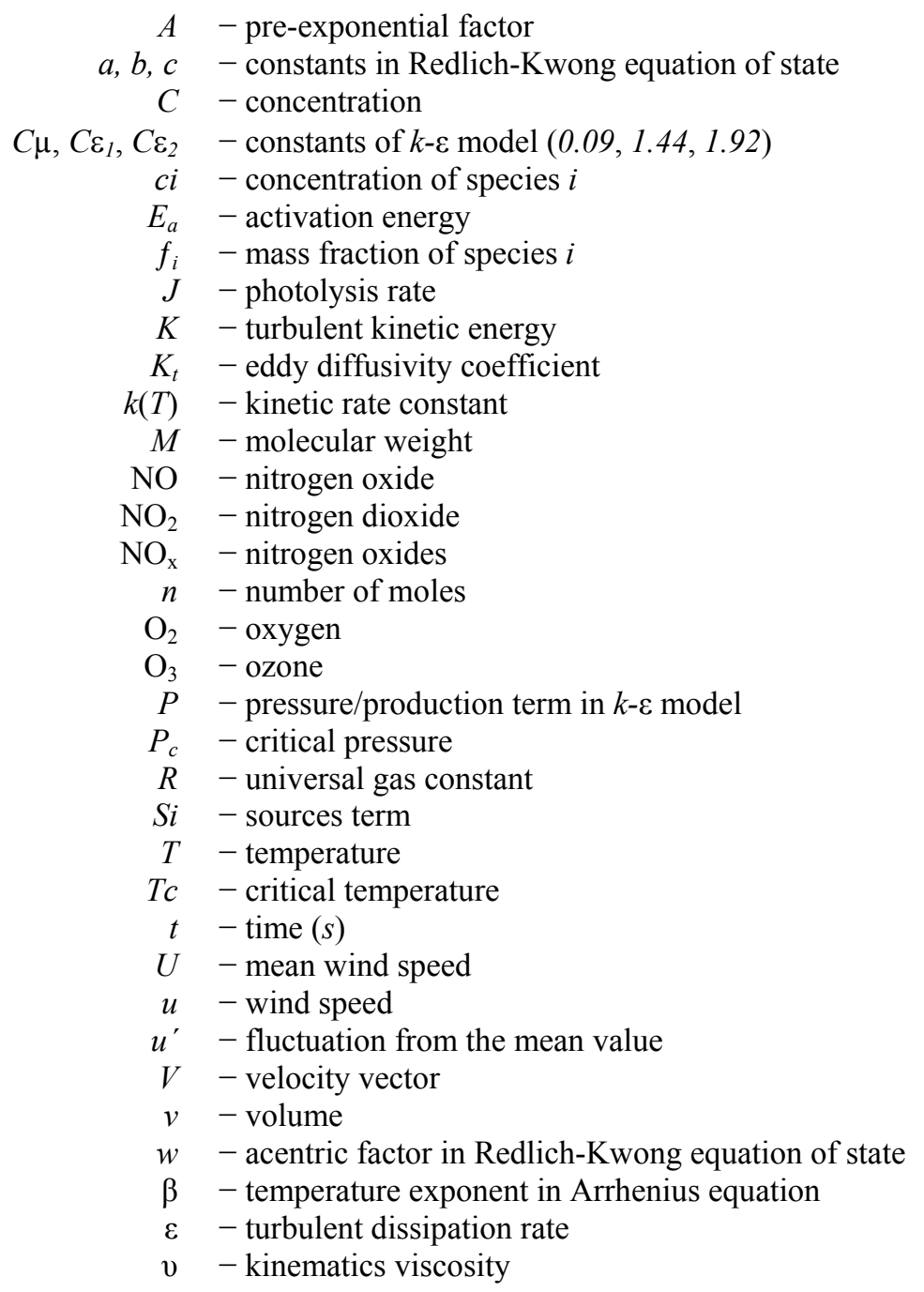




$$
\begin{aligned}
v_{t} & - \text { kinematics turbulent/eddy viscosity } \\
\rho & - \text { density of the fluid } \\
\sigma_{k}, \sigma_{\varepsilon} & - \text { constants in } k-\varepsilon \text { model }(1,1.3)
\end{aligned}
$$

\section{References}

[1] Hoydysh W.G. and Dabberdt W.F. (1988): Kinematics and dispersion characteristics of flows in asymmetric street canyons. - Atmospheric Environment, vol.22, No.12, pp.2677-2689.

[2] Garmory A., Kim I.S., Britter R.E. and Mastorakos E. (2009): Simulations of the dispersion of reactive pollutants in a street canyon, considering different chemical mechanisms and micromixing. - Atmospheric Environment, vol.43, No.31, pp.4670-4680.

[3] Kastner-Klein P. and Plate P.J. (1999): Wind-tunnel study of concentration fields in street canyons. - Atmospheric Environment, vol.33, No.24-25, pp.3937-3979.

[4] Meroney R.N. and Pavageau M. (1996): Study of line source characteristics for 2-D physical modelling of pollutant dispersion in street canyons. - Journal of Wind Engineering and Industrial Aerodynamics, vol.62, No.1, pp.37-56.

[5] Oke T.R. (1988): Street design and urban canopy layer climate. - J. Energy and Buildings, vol.11, No.1-3, pp.103-131.

[6] Cheng W.C., Chun-Ho L. and Dennis Y.C.L. (2009): On the correlation of air and pollutant exchange for street canyons in combined wind-buoyancy-driven flow. - Atmospheric Environment, vol.43, No.24, pp.3682-3690.

[7] Johnson G.T. and Hunter L.J. (1999): Some insights into typical urban canyon airflows. - Atmospheric Environment, vol.33, No.24-25, pp.3991-3999.

[8] Rotach M.W. (1995): Profiles of turbulence statistics in and above an urban street canyon. - Atmospheric Environment, vol.29, No.13, pp.1473-1486.

[9] Sini J.F., Anquetin S. and Mestayer G. (1996): Pollutant dispersion and thermal effects in urban street canyons. Atmospheric Environment, vol.30, No.15, pp.2659-2677.

[10] Merah A., Noureddine A. and Abidat M. (2016): CFD photochemical modelling in an urban street canyon. - Der Pharma Chemica, vol.8, No.4, pp.418-424.

[11] Giorgio S.S. (1979): Application of the Redlich-Kwong-Soave Equation of state to solid-liquid equilibrium calculations. - Chemical Engineering Science, vol.34, No.2, pp.225-229.

[12] Baker J., Walker Helen L. and Cai X. (2004): A study of the dispersion and transport of reactive pollutants in and above street canyons - a large eddy simulation. - Atmospheric Environment, vol.38, No.39, pp.6883-6892.

[13] Stern R. and Yamartino R.J. (2001): Development and first evaluation of micro-calgrid: a 3-D, urban-canopyscale photochemical model. - Atmospheric Environment, vol.35, No.1, pp.149-165.

[14] Yoshihide T., Akashi M., Ryuichiro Y., Hiroto K., Tsuyoshi N., Masaru Y. and Taichi Shirasawa S. (2008): AIJ guidelines for practical Applications of CFD to pedestrian wind environment around buildings. - Journal of Wind Engineering and Industrial Aerodynamics, vol.96, No.10-11, pp.1749-1761.

[15] Baik J.J., Kang Y.S. and Kim J.J. (2007): Modelling reactive pollutant dispersion in an urban street canyon. Atmospheric Environment, vol.41, No.5, pp.934-949.

[16] Bright V.B., Bloss W.J. and Cai X. (2013): Urban street canyons: coupling dynamics, chemistry and withincanyon chemical processing of emissions. - Atmospheric Environment, vol.68, pp.127-142.

[17] Yucong M., Shuhua L., Yijia Z., Shu W. and Yuan L. (2014): Numerical study of traffic pollutant dispersion within different street canyon configurations. - Advances in Meteorology, vol.2014, ID 458671, pp.1-14.

[18] Triantafyllou A.G., Zoras S., Evagelopoulos V., Garas S. and Diamantopoulos C. (2008): DOAS measurements above an urban street canyon in a medium sized city. - Global NEST Journal, vol.10, No.2, pp.161-168.

Received: May 22, 2018

Revised: December 18, 2018 